\title{
Why Invest in Early Child Development?
}

\author{
Associate Prof. Dr. Hem Sagar Rimal, MBBS, MD (Paediatrics), MPH, Fellowship in Development Paediatrics \\ Department of Paediatrics \\ Birat Medical College \& Teaching Hospital, \\ Tankisinuwari-02, Morang, Nepal
}

\section{Citation}

Rimal HS. Why Invest in Early Child Development ? BJHS 2016, 1(1) 1: 1-2

Every day, millions of children in the developing world are being blocked from reaching their true potential because of the lack of awareness about early child development, not only from their families but from their communities and even their governments. Although early child development may not seem like a subject of utmost importance, especially when there is so much to worry about in developing and impoverished societies but it is something that really does need to be addressed, because with the proper management of early child development comes the sustainable alleviation of other more visible problems. Child development refers to the ordered emergence of interdependent skills of sensorimotor, language, cognitive and social-emotional through maturation of complex nervous system. ${ }^{1}$

Early child welfare and mental health is a topic of great discussion in the recent years, as we have only just begun to understand the impact that the first few years of our lives may have on the remainder of our time on this earth. The growing brain of a toddler can be molded and shaped into almost anything. The growing mind is strengthened by positive and stimulating experiences and weakened by negative experiences or the lack of experiences in general. Toxic stress, of any shape or form will have a negative impact on the child's mental health and their growth. The lack of proper nutrition, sleep disturbances, irregular noises, separation from parents are just some of the highly impactful negative experiences that a child can go through, that will play a great role in determining the soundness of a person's mind and body once they reach maturity. ${ }^{2}$ Poverty is the mother of all factors directly contributing to the lack of child development in the developing world. Everything begins and ends with poverty in disadvantaged households. Illiteracy and Malnutrition are just two of the big problems that have a direct impact on child welfare that stem directly off from poverty. ${ }^{3}$
Research on neuroscience of brain development shows that by 3 years of age, brain development including functional pathways is largely completed. The ways in which a child responds and acts later in life are significantly determined by these functional pathways. Research has also put behind the debate of nature and nurture. The Plasticity of the brain during these first few years of a child's life is much more beneficial than any genetic advantages they may have been born with. Without the proper care and stimulus, any inherent talent may prove obsolete. During these first 3 years, children experience the world around them in a much more complex way than they do in the latter years of their lives. They grasp the world with all of their senses. This way of learning with all of their senses allows babies to create vast neuronal networks and understand the world in a more complete way. To optimize this way of learning, investment in stimulus is absolutely essential. Children need to experience a world filled with stimulating, sights, sounds, smells and people. There are many cross sectional studies of high risk children that revealed associations between concurrent stunting and poor school progress or cognitive ability. Stunted children compared to non-stunted children, were less likely to enroll late and to attain lower achievement levels for their age. This means they will not attain their full development potential. ${ }^{4}$

The Heckman Equation, Invest develop and sustain for gain is a very famous equation applicable in the field of developmental paediatrics. It tells us very clearly that the Investment, Development and the Sustainability of Childhood education, Stimulus and Wellbeing is essential to the success of not only the child but the entire generation. According to Heckman, the earlier the investment in the child, the more beneficial it will turn out to be for them in the long run. Research has shown that, the amount of positive, stimulating and educational experiences along with proper nutrition and parenting a child has in their pre-school years is much more impactful on the developing brain than those acquired during their school and college years. ${ }^{5}$ 
Although society's perception of the importance of child welfare has changed significantly since the turn of the millennia in most developing countries, there still isn't enough government intervention with regards to child welfare for there to be significant visible changes in the overall strength of the population. The prevalence of so many child development problems in the developing world shows just how much more work is needed to improve the general wellbeing of the children and the population of the countries in general. The investment in early child development is the most efficient and foolproof investment that could possibly be made if done well. The low cost and high reward nature of early child investment is surely the best way of ensuring a brighter future for the coming generations. A study was done by Harvard University showing the trajectory of brain development in 3 separate "classes" of people, the Upper, Middle and Disadvantaged classes. It clearly showed that for the first few months of their lives all of the babies receive just enough stimulus to show the same patterns of growth, but once the babies start to adapt to the changes around them, the trajectory of growth greatly steepens with the upper, somewhat rises with the middle, and stays relatively flat for the disadvantaged family. In this way, we can presume that the lack of proper care, infrastructure and the inability to invest in early child development of the disadvantaged families was a destructive force in the proper growth and development of the child. Due to this, there isn't a way for the disadvantaged children to escape from the poverty, hence continuing this disastrous cycle of Poverty and Stagnated Child Development. $^{6}$

In Nepal, like in many other south East Asian developing countries, there is progress being made, even though it may not be in leaps and bounds. On 15 June 2016 a National Conference on Early Childhood Development was held in Kathmandu. The purpose of the conference was to raise awareness about the importance of Early Child Development. The conference was held to urge people to invest in Early Child Development with a goal to create a sustainable and efficient growing environment for the children of the future. Also a recent education bill was passed which integrates ECD within basic education. This is an important step when we are striving for change to begin at the simplest levels. This, along with the growing interest of pediatricians in this country towards ECD shows a brighter future for children in Nepal. Although there are steps being taken, there is still plenty of work to be done. Data collection is the first step to find out the magnitude of problem, followed by successful intervention and finally the formation of an efficient system to sustain the intervention. We need to keep working towards development, if not for the sake of our children, then for the sake of theirs.

\section{REFERENCES}

1. Grantham-McGregor S, Cheung YB, Cueto S, Glewwe P, Richter L, Strupp B. Developmental potential in the first 5 years for children in developing countries. Lancet. 2007;369(9555):60-70.

2. Garner AS, Shonkoff JP. Early childhood adversity, toxic stress, and the role of the pediatrician: translating developmental science into lifelong health. Pediatrics. 2012;129(1):e224-31.

3. Walker SP, Wachs TD, Gardner JM, Lozoff B, Wasserman GA, Pollitt E, et al. Child development: risk factors for adverse outcomes in developing countries. Lancet. 2007;369(9556):145-57.

4. Mock PR LJ. Childhood malnutrition and schooling in the terai region of nepal. J DEV ECON. 1986;20:33-52.

5. Campbell F, Conti G, Heckman JJ, Moon SH, Pinto R, Pungello $E$, et al. Early childhood investments substantially boost adult health. Science. 2014;343(6178):1478-85.

6. Engle PL, Black MM, Behrman JR, Cabral de Mello M, Gertler PJ, Kapiriri L, et al. Strategies to avoid the loss of developmental potential in more than $\mathbf{2 0 0}$ million children in the developing world. Lancet. 2007;369(9557):229-42. 